\title{
ENGINEERING FEATURES OF CHESAPEAKE AND DELA- WARE, AND NORFOLK-BEAUFORT WATERWAYS ${ }^{1}$
}

\author{
By Major C. A. F. Flagler, \\ Corps of Engineers, U. S. Army.
}

The waterway from Boston to Beaufort Inlet has many links partially constructed: the Cape Cod Canal, the Delaware and Raritan Canal, the Chesapeake and Delaware Canal, the Dismal Swamp and Albemarle and Chesapeake canals paralleling each other, and the Core Creek cut now being made by the government from Beaufort Harbor to Pamlico Sound. All of these, however, are for a generally shallow draft commerce, ten feet at low water being about the prevailing depth. They are what may be termed barge canals. The great Atlantic waterways that we are discussing include this inland chain of artificial channels and also great natural channels such as Long Island Sound, the Delaware and Chesapeake bays. All of these large natural waters are being made navigable by the general government for ships of the largest draft and the connecting artificial channe!s should offer in the near future equal advantages. There should be no weak links in the chain.

\section{The Two Waterways}

The Norfolk-Beaufort waterway has its southern terminus at Beaufort Inlet, N. C., passes by a land cut, utilizing Core Creek, into the waters of Pamlico Sound, thence through Croatan Sound it passes into and crosses Albemarle Sound, and thence, utilizing small sounds and rivers, it passes into Norfolk Harbor through the Elizabeth River. Funds were partially appropriated in the last river and harbor act of Congress, and work is now in progress on the southern end of the waterway. This waterway is intended only for light draft traffic, mainly towed barges. Its main advantages are, that it opens up to water transportation the productive section of eastern North Carolina, and offers a safe inland passage for the smaller coastwise boats by dangerous Cape Hatteras. The two private canals referred to, the Dismal Swamp Canal and the Albe-

1A paper read before the Atlantic Deeper Waterways Conference, Philadelphia, November $19,1907$. 
marle and Cheasapeake Canal, now furnish light draft channels from Norfolk Harbor into Albemarle Sound.

The Chesapeake and Delaware Canal route reported upon to Congress is that of the present Chesapeake and Delaware Canal, from Delaware City, Delaware, to Chesapeake City, Maryland. This route has been carefully surveyed and investigated by borings, and estimates submitted for ship channels of thirty-five and thirtyfoot depths. These deeper canals lengthen the present artificial waterway by several miles of channel which must be dredged on the shallow foreshore of the Delaware River, and in the waters of Back Creek, Elk River, and Chesapeake Bay.

\section{The Terrene}

The country in which these waterways lie is practically of the same formation from northern New Jersey to any point on the South Atlantic coast that may be selected for an ocean terminus. The terrene is the great Atlantic coast plain about roo miles wide, measured inland from the shore and extending out under the ocean for fifty to one hundred miles to the edge of the Continental plateau. It consists of rock of the tertiary period covered from thirty to two hundred feet deep with glacial drift, and broken at intervals by the deep gorges that were once the beds of the great glaciers of the Delaware, the Susquehanna, the Hudson, and others. Along the ocean shores this soil is supplemented by the sand brought down by wave action from the rocks of older geologic formation abutting on the coast in New England, Nova Scotia, Newfoundland and Labrador. All of this drift and sand is easily moved and molded by the forces of nature. The shore line is universally of sand, and generally the ocean shore is merely a narrow cordon of sand separating the ocean from the chain of inland waters. At places, this cordon is in two or even three distinct lines. I am indebted to a paper by Major Cassius E. Gillette ${ }^{2}$ for the following theory of the formation of these cordons, given only in part:

The sand driven shoreward (by the waves) up the gentle slope of the Atlantic Continental shelf gradually formed itself into an under water ridge parallel to the shore line. As it approached the surface, it was washed down by the ebb tide. This washing was irregular as to amount and location, and ultimately the tidal escape was through low places, gradually washed deeper while the waves, unopposed, built the intervening stretches into sand islands, and the low places became entrances into sounds or bays.

2Sea Coast Harbors in the U. S., International Engineering Congress, St. Louis, 1904. 
A shore formed in this way naturally enclosed only shallow agoons; but some of these, of large extent, eventually by wave and tidal action in their own areas, produced the deeps and shallows that we now find.

\section{The Engineering Features}

From Beaufort to Norfolk and from the Chesapeake to the Delaware, waterways must be located in this low-lying coastal plain, with its shallow streams and broad sheets of water. The question of construction of a waterway presents as its first and most difficult feature, the choice of route. There are so many offering nearly equal advantages, or equally balanced advantages and disadvantages, that it is difficult to reduce even the more obvious to a reasonable number for careful consideration. On the Norfolk-Beaufort route the waterway was divided for consideration into three divisions, and it was deemed absolutely necessary to examine carefully five routes in the first division, six in the second, and two in the third. From the Chesapeake to the Delaware, nine routes have been carefully considered. For both waterways many other routes have been proposed and considered, but not examined. On the Beaufort-Norfolk waterway the decision is rendered more difficult by the question of depth-some routes offering greater advantages for a ten or twelvefoot depth which disappear when a sixteen-foot depth is considered -these being the three depths that have been reported to Congress with definite estimates. It is probable that the best routes for these depths would yield in parts to other routes were a thirty-five foot ship canal contemplated. The great present demand for canals, to become greater in the future, will eventually require large ship canals along all the sections of the great route we are discussing as a whole. It is the part of foresight and economy that each route should be located with a view to the construction of a channel for the largest commercial ships. If channels of such dimensions are not needed at present or funds are not available for their construction, let the modest canal barge be constructed, of twelve to sixteen-foot depth; but with every provision made in the acquisition of land and the location of route to permit its future enlargement to meet any commercial demand that may arise. The projects for both of these waterways contain no provision for locks, and the expensive work of reconstructing locks of larger size will not militate against 
enlargement of the waterways at any time by any increment, large or small.

The construction along both routes, of either a shallow barge canal or of a deep draft ship canal, is entirely feasible. The geologic formation is such as to offer variety of material: hard sands and gravels, marsh land, upland soils, decomposed peaty strata and the real quicksand. No rock is anticipated along these two routes. The project for both canals is for tide-level canals, eliminating the many problems arising with summit canals, in the arrangements needed for water supply and for avoidance of interference with local streams and drainage. Excavation by well-known engineering methods in both land and water cuts will constitute the bulk of the work. A troublesome quicksand on the Chesapeake and Delaware Canal, 7,000 feet long and forty feet thick, will offer interesting, but not difficult, study for its passage. Sliding side banks in one locality present difficulties to overcome. Permanent organization of plant and personnel must be considered and provided to meet the necessary work in the maintenance of channel depths and widths after completion, the removal of ice, the lighting and policing of the canal, and the repairs of banks, revetments and appurtenances. All of these have been carefully considered in the projects and estimates for these waterways, but their details, while of technical interest to the engineer, have no place in such a conference as ours.

In the further prosecution of the construction of the waterways along the route, and in discussion relative thereto, there are two obstructive and misleading engineering fallacies that will be certain to play a part on these canals as they have on those of the past.

\section{Land and Water Cuts}

A glance at the geography of our Atlantic coast shows an almost continuous line of bays, sounds, lakes, rivers and creeks paralleling the shore of the ocean from Florida to Cape Cod. It would appear at first sight that the excavation of a channel across the short intervals of land separating the links of the chain would create a magnificent waterway for commerce. This is not true; most of the stretches of water that we see on the map are so shallow that the excavation of channels is as much needed in them as through the land; and, furthermore, which is the point I wish to 
bring out, channels dredged in bodies of shallow water are frequently more expensive than through land cuts, especially along this route. "All is not gold that glitters," and similarly, from a commercial and engineering standpoint, all is not water that is printed blue on the map. The land along most of the territory to be traversed by our route is low-lying marsh in which excavation is easy. It is frequently land of little or no value. (In my present district, which comprises part of five states, some thirty or more such cuts have been made, and all land required has been deered to the United States free of cost.) Disposition of dredged material becomes simplified in land cuts, as it can be easily placed ashore where it will not return to the constructed channel, and the deposit of silt in such a channel will be only that washed from the channel itself, giving a minimum for annual maintenance of the channel.

On the other hand, a channel across a wide wind-swept area of shallow water with irregular tides and currents flowing across the line of channel, presents many difficulties not present in the land cuts. While the excavation in dredging may be less, the material dredged cannot usually be placed along the sides of the artificial channel, as a large portion of it would, in all likelihood, return to the channel. It must, therefore, be frequently towed long distances to a suitable dumping ground, and frequently pumped ashore from an artificial dumping basin by means of additional and costly plant. Still more important, the exposure of these channels to wave and current action makes their navigation difficult and their maintenance costly. In the higher latitudes these open channels are also rendered difficult and dangerous to navigation owing to the cross passage of large fields of moving ice during the winter season. The method of handling boats out of Baltimore through an open channel affected by ice fields will show the difficulties arising. I quote from a report of the war department:

The experience of ice boats in Baltimore Harbor and the approaches thereto is very interesting and instructive. Within the harbor the ice formed in place constituted what is known as still ice. The traffic of the port and the passage of the ice boat through keep an open channel, the navigation of which presents no difficulty. The ice being "still" a channel or passage broken through it remains stationary in position. This is the state of the case until a point between North Point and the Seven Foot Knoll is reached. Here the ice is a drifting field. A channel way being broken through it drifts with the field. Therefore a passage broken through this 
field and over the deep-dredged channel immediately moves off this channel, and in a short space of time, the work must again be gone over before any vessels can pass along the dredged way. * * * When ice is thus drifting, the method of procedure is the following: One or more vessels desiring to proceed to sea are towed by a tug boat and convoyed by the ice boat which precedes the tow. To allow for the drifting of the broken passage through the ice, the ice boat works not over the dredged cut but on the side from which the ice is drifting. The tow being at a proper distance behind can move along the dredged channel as the ice cut is passing over it.

These statements will, I think, show you that occasionally the land cut is more economical in construction, and still more frequently in maintenance. Generally the natural bodies of water offer the cheapest and best route, but the economy resulting from occasional resort to land cuts even paralleling such bodies of water should not be lost to sight, and not ridiculed when suggested.

\section{Tide-Locks}

The second fallacy is more dangerous and far-reaching than the first. It is the well-known tendency to consider tide-locks necessary on all tide-level canals to prevent dangerous flow in the canals due to the rise and fall of the tide. This tendency is not confined to the lay mind, but extends to many of our most celebrated hydraulic engineers. President Shonts, of the Isthmian Canal Commission, when the discussion of a tide-level or high-level canal was under consideration, was widely quoted as saying that "one lock (tide) being a necessity, the addition of four others becomes less objectionable." Was one lock a necessity if a tide-level canal had been decided upon? Many of our best engineers think not. During the French régime on the canal, a study of the subject by the most thorough students of the hydraulics of the canal in France, led to reports that it was not necessary, founded on careful calculation and investigation; and these reports were concurred in by the French Academy in 1887 . Mr. Clemens Herschel, ${ }^{3}$ one of the most noted of our hydraulic engineers, in an article questioning the necessity for a lock on a tide-level canal at Panama, says: "The idea of the Suez Canal was denounced by leading engineers of the day as an impossible work if built without a tide-lock, and held up to the scorn and ridicule of men by these same engineers and by some of the greatest statesmen of that period, as a bubble

JEngineering News, March 22, 1906. 
scheme, sure to bring ruin to who would support it. . . . . Now, fifty years later, it is paying $\$ 17,000,000$ annually to its stockholders, and a proposition to put a lock into it would be regarded as the suggestion of a maniac." The construction of the lockless canal of Corinth was delayed over 2,000 years after it was first projected owing to this same fallacy. It is now navigated with ease. An expensive tide-lock was put in the Albemarle and Chesapeake Canal, in Virginia, because a difference of level of eleven feet sometimes existed between the water at the ends of the canal, eighteen miles long. The lock is seldom closed, and then only to prevent erosion of the banks, which could have been easily met by revetment.

I think I can explain in a few words the cause of the existence of this fallacy. Difference of water level at two ends of an open waterway always causes flow, which increases as a direct function of the height. If the difference is constant, the flow is constant, and may be easily computed. Where the differences at both ends are caused by tides, the resultant difference is a constantly varying one. The head of water is rapidly changing, while the velocity engendered by it is slowly coming into life, retarded by friction and inertia. Long before a velocity equals that caused by the extreme tidal head, it is beginning to fail from a reversal of the tidal conditions. It results that currents thus engendered by constantly varying tidal heads never reach or even approach nearly the velocities corresponding to constant heads, equal to the tidal differences. Intricate formulæ, generally empirical, have been devised for making computations of velocities in these cases, but they are, I regret to say, little studied by many who should understand their use, and excessive currents are frequently predicted which have been computed for static heads. To prevent delays to vessels passing through canals, the banks should be revetted sufficiently to permit a fair rate of speed of the vessels without injury to the banks. Any current that an ordinary vessel can stem will not injure banks that permit a rate of five knots to passing vessels. Great difference of tidal levels at the ends of short open canals does in some cases require tide-locks, but these great differences do not exist in the waterways under consideration.

Pardon my digressing here to say, for fear of being misquoted, that I have always regarded a high-level lock canal as the best 
type at the Isthmus of Panama, but for reasons not pertinent to this paper, and certainly not to avoid tide-locks.

Locks are, of course, necessary where a constant difference of level exists of considerable height between the ends of a canal to permit safe navigation, and they are frequently used for economical reasons to pass a high summit level, even when the ends of the canal may be practically at the same level. The Delaware and Raritan Canal doubtless requires consideration on these points but it is my positive and carefully considered belief that no lock of any description will be required in any part of the chain of waterways from New Jersey to the Carolinas. There may be many present who disagree with me on these points, but I ask you all, in considering future references to this waterway in the press or elsewhere, to take with a grain of salt any statement made as to the absurdity of land cuts paralleling bodies of water, or the necessity for locks on a tide-level canal.

\section{Conclusion}

There remains only for me to say that there is nothing, from an engineering standpoint, to prevent the construction of a ship canal from Beaufort, N. C., to Norfolk, Va., and across the peninsula of Delaware and Maryland. The same is doubtless true of other portions of the great Atlantic waterway, and the engineeting talent of the country awaits only the provision of the necessary funds, whether from the national government or from private or corporate sources, to place at the service of the country's comn:erce this most magnificent highway. 